Dokuz Eylül Üniversitesi-Mühendislik Fakültesi

Fen ve Mühendislik Dergisi

Cilt 20, Sayı 59, Mayıs, 2018
Dokuz Eylul University-Faculty of Engineering Journal of Science and Engineering Volume 20, Issue 59, May, 2018

DOI: $10.21205 /$ deufmd.2018205955

\title{
MFI Tipi Zeolit Membranların Yüksek Sıcaklıkta Geri Döngülü Akış Sisteminde Sentezi
}

\section{Berna TOPUZ ${ }^{* 1}$, Aylin Önder SAKA ${ }^{2}$, Halil Kalıpçılar ${ }^{3}$}

${ }^{1}$ Ankara Üniversitesi, Mühendislik Fakültesi, Kimya Mühendisliği Bölümü, 06100, Ankara. (ORCID: 0000-0002-6980-3296)

${ }^{2}$ Ortadoğu Teknik Üniversitesi, Mühendislik Fakültesi, Kimya Mühendisliği Bölümü, 06100, Ankara (ORCID: 0000-0000-0000-0000)

${ }^{3}$ Ortadoğu Teknik Üniversitesi, Mühendislik Fakültesi, Kimya Mühendisliği Bölümü, 06100, Ankara (ORCID: 0000-0002-4362-8215)

(Alınış / Received: 07.06.2016, Kabul / Accepted: 03.04.2018, Online Yayınlanma / Published Online: 15.05.2018)

Anahtar Kelimeler Zeolit membran, MFI, Geri döngülü akıș sentezi, Gaz ayrımı
Özet: Bu çalışmada, MFI tipi zeolit membranlar makro gözenekli destekler üzerinde yüksek sıcaklık ve basınç altında geri döngülü akıș sisteminde sentezlenmiş ve MFI tipi zeolit membranların özellikleri üzerine membran sentez sıcaklığının etkisi incelenmiştir. Membranların sentezi $140-160^{\circ} \mathrm{C}$ aralığında iç tarafı nano boyutta MFI tohum kristalleri ile kaplanmış alümina tüpler üzerinde yapılmıştır. Membranlar ve sentez sırasında eş zamanlı olarak oluşan toz malzemeler X-ıșını kırınımı, taramalı elektron mikroskobu, ve tanecik boyut dağılımı ölçümleri ile karakterize edilmiştir. Elde edilen membranlarda $n-\mathrm{C}_{4} \mathrm{H}_{10}$ /iso$\mathrm{C}_{4} \mathrm{H}_{10}$ ile yapılan seçicilik testlerinde ideal seçicilik değerinin 20'ye ulaşması uygulanan sentez tekniğinin yüksek kalitede membran üretimine olanak sağlayacağını göstermektedir.

\section{Synthesis of MFI Membranes through Recirculated Flow at Elevated Temperatures}

\begin{tabular}{ll}
\hline Keywords & Abstract: In this study, MFI type zeolite membranes were \\
Zeolite & synthesised in a recirculating flow system at elevated \\
membrane, & temperatures. MFI membranes were prepared on the inner \\
MFI, & surface of the seeded tubular alumina supports in the $140-160^{\circ} \mathrm{C}$ \\
Recirculated flow & temperature range. MFI membranes were characterized by \\
system, & scanning electron microscopy, X-ray diffraction and single gas \\
Gas separation & permeation experiments. The best membrane had a $n-\mathrm{C}_{4} \mathrm{H}_{10}$ single \\
& gas permeance of $3.6 \times 10^{-8} \mathrm{~mol} / \mathrm{m}^{2}-\mathrm{s}-\mathrm{Pa}$ and $\mathrm{n}-\mathrm{C}_{4} \mathrm{H}_{10} / \mathrm{is}_{-}-\mathrm{C}_{4} \mathrm{H}_{10}$ \\
& ideal selectivity of 20 at $25^{\circ} \mathrm{C}$. The results showed that it is \\
& possible to produce high quality MFI membranes by a \\
& recirculating flow system operating at elevated temperature.
\end{tabular}

*Berna Topuz: topuzb@ankara.edu.tr 


\section{Giriş}

Zeolitler Grup 1A ve $2 \mathrm{~A}$ elementlerinin alüminyum silikatları olan kristallerdir. Zeolitlerin yapısının temelini $\mathrm{AlO}_{4}$ ve $\mathrm{SiO}_{4}$ tetrahedrallerinin üç boyutlu çerçeve yapısı oluşturur [1]. Bu çerçeve yapısı katyonları, kanal ve birbirine bağlı boşlukları içerir. Yapılarındaki gözenek boyunun 0,4-1,2 $\mathrm{nm}$ arasinda olması nedeniyle zeolitler molekülleri boyutlarına göre seçici olarak adsorplayabilir ya da reddedebilirler [2]. MFI tip zeolitlerin iki çeşidi vardır; çerçeve yapısında alumina içerenler ZSM-5 olarak adlandırılırlar ve çerçeve yapısında alumina içermeyenler silikalit olarak adlandırılırlar. ZSM-5 kristalleri biri zig-zag diğeri düz iki kanal sisteminden oluşur. Zigzag kanalların gözenek açıklığı 0,53-0,56 nm, düz kanallarınki ise 0,51-0,55 nm'dir. Gözenekler, toplam hacmin \%33'ünü oluşturmaktadır [3].

Zeolit membranlar gözenekli bir destek malzemesi üzerinde ince bir zeolit tabakasının sentezlenmesi yöntemi ile elde edilirler. İdealde tek tip gözenek boyuna sahip bu membranlar, kimyasal olarak kararlı, ısıl ve mekanik açıdan dayanıklıdırlar. Zeolit membranların sentezi genel olarak hidrotermal yöntem ile otoklavlar içerisinde kesikli sistemlerde gerçekleştirilir. Destek malzemesi otoklavın içine yerleştirilir ve otoklavın içi sentez çözeltisi ile doldurulur. Gerekli sentez koşulları sağlanarak zeolitler destek yüzeyinde ve sentez çözeltisi içerisinde sentezlenir $[4,5]$. Destek üzerinde zeolit membran katmanı çok ince olmalı ve yüzey hataları içermemelidir. Zeolit membranın kalınlığı membranı oluşturan kristallerin sayısına ve büyük oranda büyüklüğüne bağlıdır.

Zeolit membranların endüstriyel etkin kullanımı için önemli bazı parametreler vardır. Bunlar; ayırılacak karışım için yüksek geçirgenlik ve ayırma seçiciliği, membran üretiminin tekrarlanabilir ve düşük maliyetli olması, membran geometrisinin alan/hacim oranının yüksek olmasıdır [6]. Kesikli sistemlerde büyük yüzey alanına sahip membranların sentezinde bazı problemler oluşabilir. Sentezlenecek membranın yüzey alanı arttıkça kullanılacak otoklavın büyüklüğü artmaktadır. Böylece sentez koșullarında kompozisyonun tekdüze olmaması gibi problemlerle karşılaşılabilir [7-10]. Bu da membran kalınlığının tekdüze olmamasına ve istenmeyen fazların oluşumuna [10-11] dolayısı ile membran performansının düşmesine neden olmaktadır. Ayrıca tekrarlanabilir membran üretimi zorlaşmaktadır.

Sentez çözeltisinin sentez sırasında akıtıldığı sentez sistemlerinde sıcaklık ve konsantrasyon farklılıkları önlenmektedir. Böylece endüstriyel alanda kullanılabilecek geniş yüzey alanına sahip membranların sentezlenmesi için daha homojen bir sistem elde edilmiş olmaktadır. Sentez için gerekli olan kimyasal malzemelerin tüketimi açısından geri döngülü akışlı sistemi sürekli akışın olduğu sistemlere göre daha ekonomiktir [10]. Yüksek sıcaklık ve yüksek basınca dayanıklı akışlı bir sistem homojen, kaliteli ve tekrarlanabilir membranların sentezi için umut vericidir.

Literatürde membran hazırlanmasında akışlı sistemin kullanıldığı sınırlı sayıda çalışma vardır [10-14]. Richter ve arkadaşları [12] sentez çözeltisini bir rezervuardan diğerine $25 \mathrm{~cm}$ 'lik alümina tüpler ve kılcal tüpler vasıtası ile 0,25 $\mathrm{cm} /$ dak hızla akıtarak 72 saatlik bir sürede ZSM-5 membranların sentezini gerçekleștirmiştir. Sentez $180^{\circ} \mathrm{C}$ gerçekleştirilmiş olup sentez çözeltisinin otoklavdan akışı basınçlı azot ile itme yöntemiyle yapılmıştır. Çulfaz ve arkadaşları [10] geri döngülü akış sisteminde, atmosferik basınç altında sentez sıcaklığ $80^{\circ} \mathrm{C}$ ve $95^{\circ} \mathrm{C}$ olmak üzere MFI membranlar 
sentezlemişlerdir. Sentez tekdüzeliği sistem yağ yerleștirilerek sağlanmıştır.

sıcaklığının banyosuna

Literatürde MFI tipi zeolit membranlar genellikle $160^{\circ} \mathrm{C}^{\prime}$ den yüksek sıcaklıkta ve kendiliğinden oluşan basınç altında üretilmektedir. Bu sıcaklıklarda üretilen membranlar düşük sıcaklıklarda üretilen membranlara göre daha kalın, daha düşük geçirgenliğe sahip ancak daha seçici olmaktadır. Tablo 1'de literatürde çalışılan MFI membranların $n-\mathrm{C}_{4} \mathrm{H}_{10}$ geçirgenlik değerleri ile $n$ - $\mathrm{C}_{4} \mathrm{H}_{10} /$ iso$\mathrm{C}_{4} \mathrm{H}_{10}$ ideal seçicilik değerleri özetlenmiştir.

Bu çalışmada MFI tipi zeolit membranlar alumina destekler üzerinde geri döngülü akış sisteminde 140 ve $160^{\circ} \mathrm{C}^{\prime} \mathrm{de}$ sentezlenmiş ve membran performansları tek gaz geçirgenlik ölçümleri ile $\left(\mathrm{H}_{2}, \mathrm{~N}_{2}, \mathrm{CH}_{4}, n-\mathrm{C}_{4} \mathrm{H}_{10}\right.$ ve iso$\mathrm{C}_{4} \mathrm{H}_{10}$ ) test edilmiștir. Uygulanan yöntem ile klasik kesikli sistemde elde edilenlere göre daha kaliteli ve yüksek performanslı membranların üretilmesi amaçlanmıştır. Geri döngülü akış sisteminin kullanımı ile endüstriyel kullanılabilecek uygulamalarda boyutlarda membranların üretiminde daha homojen sentez koşulları oluşturmak, daha az kayıp ve çevreye duyarlı üretim yapmak gibi önemli avantajlar sağlayacağı düşünülmektedir.

\section{Materyal ve Metot}

\subsection{Kullanılan kimyasallar}

Tohum kristallerinin ve membranların sentezinde, LUDOX HS-40 kolloidal silika (Aldrich, suda ağırlıkça \%40), LUDOX AS30 kolloidal silika (Sigma Aldrich, suda ağırlıkça \%30), tetra propil amonyum hidroksit (TPAOH, Merck, suda ağırlıkça $40 \%$ ), ve mineralsiz su kullanılmıștır.

Membran desteği olarak $4,5 \mathrm{~cm}$ boyutunda parçalar halinde kesilmiş iç ve dış çapı sırasıyla $0,7 \mathrm{~cm}$ ve $0,85 \mathrm{~cm}$ olan $\alpha$-alümina $\left(\alpha-\mathrm{Al}_{2} \mathrm{O}_{3}\right)$ tüpler kullanılmıştır (Fraunhofer-IKTS). Tüpler iç yüzeyinde $200 \mathrm{~nm}$ boyunda gözeneklere sahip ince bir tabaka ve daha büyük gözenekli kalın bir tabakadan oluşmaktadır. Bu tüpler, gaz geçirgenlik deneylerinde sızdırmazlığı sağlamak amacı ile iki ucundan yaklaşık $1 \mathrm{~cm}$ olacak şekilde Duncan IN1001 Envision Glaze ile sırlanmıştır. Bunun sonucunda verimli membran alanı bir tüp için 5,5 $\mathrm{cm}^{2}$ 'dir. Sirlı membranlara $1,5^{\circ} \mathrm{C} / \mathrm{dk}$ isitma ve soğutma hızlariyla $900^{\circ} \mathrm{C}^{\prime} \mathrm{de} 1$ saat süreyle ısıl işlem uygulanmıştır.

Tablo 1. MFI tipi membranların tek gaz geçirgenlik performansları.

\begin{tabular}{|c|c|c|c|c|c|}
\hline \multirow[b]{2}{*}{ Araştırmacı } & \multirow[b]{2}{*}{$\begin{array}{l}\text { Sentez } \\
\text { Sistemi }\end{array}$} & \multirow[b]{2}{*}{$\begin{array}{c}\text { Ölçüm } \\
\text { Sıcaklığı } \\
\left({ }^{\circ} \mathrm{C}\right)\end{array}$} & \multicolumn{2}{|c|}{$\begin{array}{c}\text { Geçirgenlik } \\
\left(\mathrm{mol} / \mathrm{m}^{2} \mathrm{sPax} 10^{8}\right)\end{array}$} & \multirow{2}{*}{$\begin{array}{l}\text { İdeal } \\
\text { Seçicilik } \\
n-\mathrm{C}_{4} \mathrm{H}_{10} / \\
\text { iso- } \mathrm{C}_{4} \mathrm{H}_{10}\end{array}$} \\
\hline & & & $n-\mathrm{C}_{4} \mathrm{H}_{10}$ & $\begin{array}{c}\text { iso- } \\
\mathrm{C}_{4} \mathrm{H}_{10}\end{array}$ & \\
\hline Çulfaz ve arkadaşları[10] & Geri döngülü & 25 & 16,6 & 2,8 & 5,9 \\
\hline $\begin{array}{l}\text { Richter ve arkadaşları } \\
\text { [12] }\end{array}$ & Sürekli & 105 & 0,016 & 0,016 & 1 \\
\hline Dede,Ö.[13] & Geri döngülü & 25 & 20,6 & 7,5 & 2,75 \\
\hline Li ve arkadaşları[15] & Kesikli & 25 & 1,8 & 0,15 & 12 \\
\hline $\begin{array}{l}\text { Hedlund ve arkadaşları } \\
\text { [16] }\end{array}$ & Kesikli & 25 & 0,005 & 0,004 & 1,25 \\
\hline Noack ve arkadaşları [17] & Kesikli & 105 & 14,4 & 2,44 & 5,9 \\
\hline Tuan ve arkadaşları [18] & Kesikli & 28 & 3,4 & 0,17 & 20 \\
\hline Au ve Yeung[19] & Kesikli & 50 & 35,4 & 72,8 & 0,48 \\
\hline Yan ve arkadașları [20] & Kesikli & 30 & 0,75 & 0,041 & 18,4 \\
\hline
\end{tabular}




\subsection{MFI membran sentezi}

Membranlar geri döngülü akış sisteminde 140 ve $160{ }^{\circ} C^{\prime}$ 'de farklı sürelerde hazırlanmıştır. Her iki sıcaklık için sentez solüsyonu başlangıç molar bileşimi $1 \mathrm{SiO}_{2}: 0,2 \mathrm{TPAOH}: 19,2 \mathrm{H}_{2} \mathrm{O}$ olan sentez çözeltisi kullanılmıştır. İkincil büyüme öncesinde tüm membranlar tohumlanmiștır. Tohum kristallerinin sentezi için başlangıç molar bileşimi $1 \mathrm{SiO}_{2}: 0,375 \mathrm{TPAOH}: 19,2 \mathrm{H}_{2} \mathrm{O}$ olan sentez çözeltisi kullanılmış olup sentez sıcaklığ ve süresi sirasiyla $95^{\circ} \mathrm{C}$ ve 72 saattir. Tohumlama yöntemi olarak daldırma tekniği kullanılmıştır. Daldırarak tohumlama yönteminde alümina tüplerin dışı teflon bant ile sarılmıştır. Tüpler ağırlıkça \%0,25 oranında tohum kristallerinin su içerisinde dağıtıldı̆̆ tohum süspansiyonu içine $1,5 \mathrm{~cm} /$ saat hız ile daldırılıp, 10 dakika süspansiyon içinde bekletilip ve yine aynı hızla geri çekilmişlerdir. Tohumlanan tüpler dik duracak şekilde teflon askı yardımıyla membran sentezi için teflon içli çelik otoklavların içine yerleştirilmiştir.

Membran sentezi geri döngülü akış sisteminde teflon hortum bağlantıları olan çelik bir otoklav içinde gerçekleştirilmiştir. Kullanılan pompa ısıtılan hacmin dişında bulunmaktadır. Sentezde kullanılan çelik otoklav iki bölmeden oluşur ve geri döngülü akış sistemi Şekil 1'de gösterilmiştir.

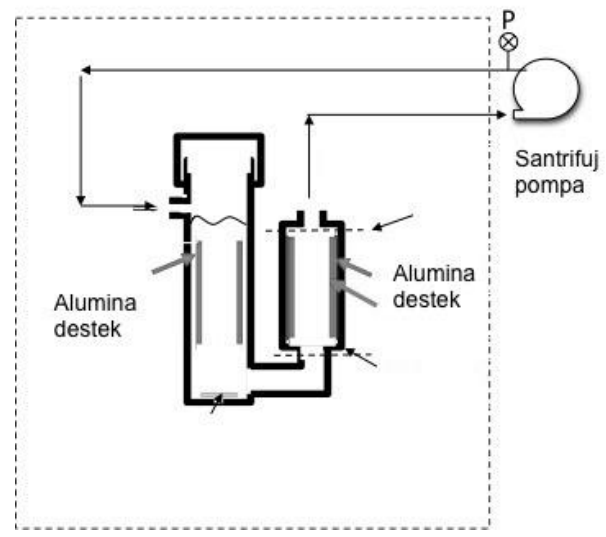

Şekil 1. Geri döngülü akıș sentez sistemi.

$\mathrm{Bu}$ otoklavda destek malzemeleri otoklavın küçük ve büyük bölmelerine yerleştirilmektedir. Büyük bölmede akış tüpün üstünden altına doğru, küçük bölmede ise tüpün altından üstüne doğrudur. Topuz ve arkadaşları [14] ZSM-5 ve SAPO-34 membranları tek bölmeli akışın sadece aşağıdan yukarıya olduğu sistemde üretmişlerdir. Sistemdeki peristaltik pompa düşük akış hızları (10 ml/dak) için, santrifüj pompa ise yüksek akış hızları (100 ml/dak) için kullanılmıştır. Sentezlenen membranların kodları, sentez sıcaklıkları ve sentez süreleri Tablo 2'de özetlenmiștir.

Tablo 2. Sentezlenen membranlar ve sentez koşulları.

\begin{tabular}{ccccc}
\hline Membran Kodu & Sentez Sistemi & $\begin{array}{c}\text { Akış Hızı } \\
(\mathrm{ml} / \mathrm{dak})\end{array}$ & $\begin{array}{c}\text { Sentez Sıcaklığ } \\
\left({ }^{\circ} \mathrm{C}\right)\end{array}$ & $\begin{array}{c}\text { Sentez Süresi } \\
\text { (Saat) }\end{array}$ \\
M1 & Geri döngülü* & 10 & 140 & 28 \\
M2 & Geri döngülü & 100 & 140 & 28 \\
M3 & Geri döngülü & 100 & 160 & 24 \\
\hline
\end{tabular}


Membranlar sentezden sonra su ile yıkanmış, $\quad 80^{\circ} \mathrm{C}^{\prime} \mathrm{de}$ kurutulmuş ve $450^{\circ} \mathrm{C}^{\prime}$ de 6 saat süre ile hava ortamında kalsine edilmiştir. Isıtma hızı $0,6^{\circ} \mathrm{C} / \mathrm{dak}$, soğuma hızı da ortalama $0,6^{\circ} \mathrm{C} / \mathrm{dak}^{\prime} \mathrm{d} ı$.

\subsection{MFI kristal ve membran karakterizasyonu}

Kesikli sistemde hazırlanan kristallerin ve geri döngülü akış sisteminde hazırlanan membranların kristal faz tanımlaması X-ışını kırınım yöntemi (XRD, Philips PW 1840) kullanılarak yapılmıştır. Örneklerde yüzde kristallik ise MFI'ye ait X sşını kırınım deseninde $2 \theta=23,2^{\circ}, 24^{\circ}$ ve $24,5^{\circ}$ deki üç tepenin kırınım şiddetleri baz alınarak aşağıdaki formülle hesaplanmıștır.

$\%$ Kristalinite $=\frac{\sum_{i=1}^{3} I_{i}}{\left(\sum_{i=1}^{3} I_{i}\right)_{\text {referans }}} \times 100$

Bütün toz örnekler içinde bu üç tepenin kırınım şiddetleri toplamı en yüksek olan örnek \%100 kristalinite referans olarak belirlenmiş, diğer örneklerin kristallik derecesi de bu ürünün kırınım şiddetleri toplamına oranlanarak bulunmuştur.

Membran morfolojileri ve kalınlıkları taramalı elektron mikroskobu (SEM, Jeol JSM-6400) kullanılarak incelenmiştir. Kesikli sistemde hazırlanan tohum kristallerin ortalama tanecik boyutu Dinamik ışık saçılımı (DLS) yöntemi ile belirlenmiştir. Tek gaz geçirgenlik ölçümleri sonu tıkalı bir membran modülüyle $25^{\circ} \mathrm{C}$ ve $150^{\circ} \mathrm{C}^{\prime}$ de $\mathrm{H}_{2}, \mathrm{~N}_{2}, \mathrm{CH}_{4}$, $n-\mathrm{C}_{4} \mathrm{H}_{10}$ ve iso- $\mathrm{C}_{4} \mathrm{H}_{10}$ gazları ile kalsine edilmiş membranlarla yapılmıştır. Ölçümler sabit basınç, değişken hacim yöntemiyle yapılmıştır. Geçen akımın basıncı atmosferik basınç $(0,9 \mathrm{~atm})$ iken besleme tarafının basıncı da 1,9 atm olarak ayarlanmıștır. Bu yönteme göre bir modül içerisine yerleştirilen membranların besleme ve geçen kısımları arasındaki basınç farkı sabit tutularak, çıkıştaki akış hızı köpük akış ölçeri ile ölçülmüştür. Geçirgenlik $(P$; $\left.\mathrm{mol} / \mathrm{m}^{2} \mathrm{sPa}\right)$ ve ideal seçicilik $\left(\alpha_{A / B}\right)$ Denklem 2 ve Denklem 3'te verildiği gibi hesaplanmıștır.

$\mathrm{P}=\frac{\Delta V}{\frac{\Delta t}{R T}} \frac{P}{\Delta p A}$

Burada, $\frac{\Delta V}{\Delta t}$;hacimsel akış hızı $\left(\mathrm{m}^{3} / \mathrm{s}\right), \mathrm{P}$ atmosfer basıncl (Pa), $\mathrm{R}$; gaz sabiti $\left(\mathrm{Pa}^{3} \mathrm{~m}^{3} / \mathrm{mol} \mathrm{K}\right), \mathrm{T}$; oda sıcaklığ $(\mathrm{K}), \Delta p$; basınç farkı (Pa), A; membran alanı $\left(\mathrm{m}^{2}\right)^{\prime}$ dır.

$\alpha_{A / B}=\frac{\mathrm{P}_{A}}{\mathrm{P}_{B}}$

\section{Bulgular}

3.1. MFI tipi zeolit sentezinde sıcaklığın etkisinin kesikli sistemde sentez ile belirlenmesi

Geri döngülü akış sisteminde sentezlenen membranların optimum sentez sürelerini belirlemek amacıyla, kesikli sistemde farklı sıcaklıklarda sentezlenen MFI zeolitlere ait X-ıșınları kırınım desenleri Şekil 2'de verilmiștir. MFI yapısının oluştuğunu gösteren pikler $(2 \theta=7,86$; $8,75 ; 23,2 ; 24 ; 24,4)$ tüm sicaklıklarda gözlemlenmiș olup membran sentez süreleri kristalinitenin $100 \%$ olduğu sürelerde $90,125,140$ ve $160^{\circ} \mathrm{C}$ için sirasiyla $40,32,28$ ve 16 saat olarak belirlenmiştir. Belirlenen sürelerden sonra yapılan analizlerde yaklaşık olarak kristalinitenin sabit kaldığı görülmüștür. 

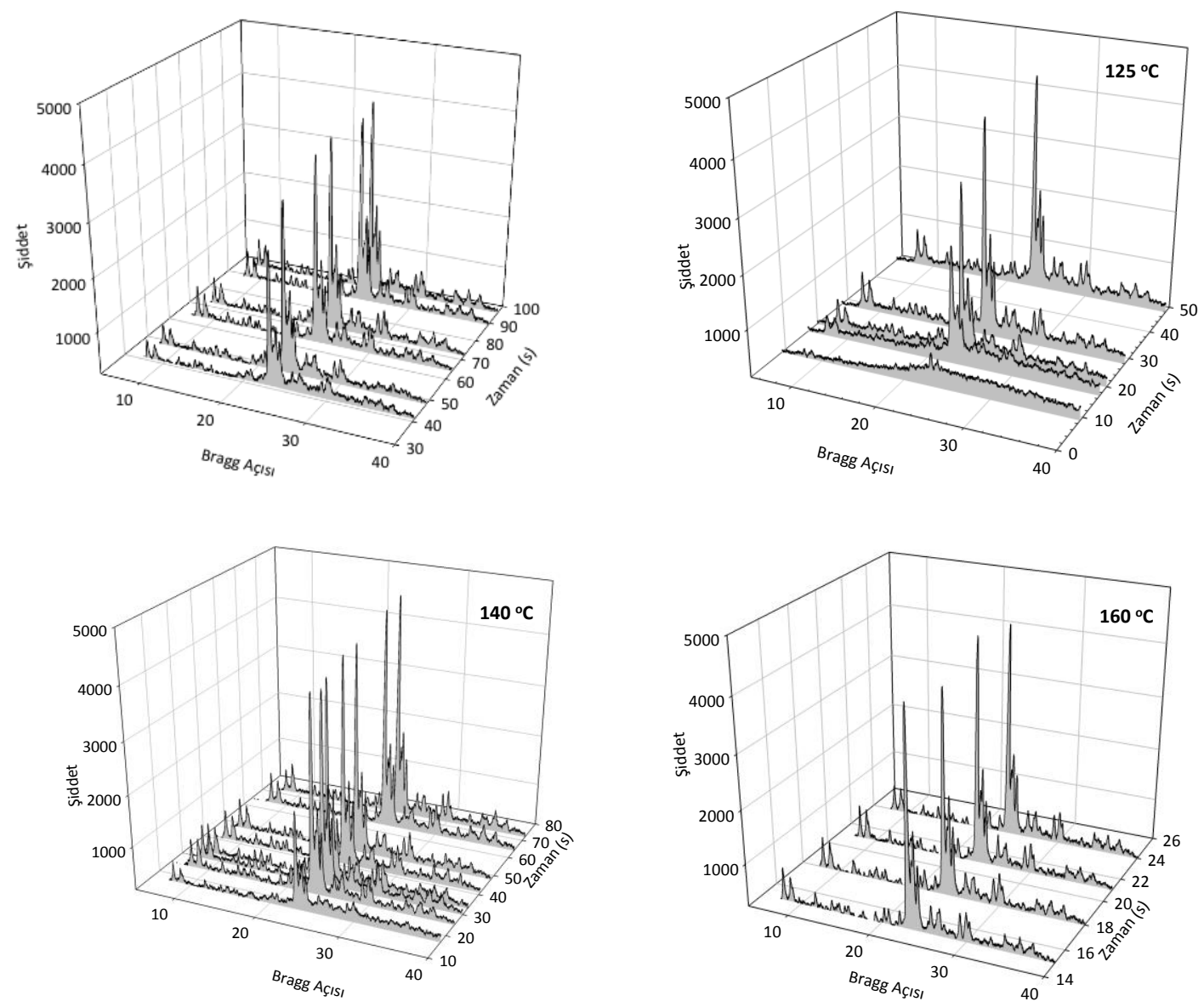

Şekil 2. $90-160^{\circ} \mathrm{C}$ sıcaklık aralığında sentezlenen MFI kristallerine ait sentez boyunca farklı zamanlarda alınan örneklerin XRD desenleri.

Kristallenme hızının sentez sıcaklığının artmasıyla birlikte arttığ gözlemlenmiştir (Şekil 3). Sentez sıcaklığının artması çekirdeklenme sürecinin kısalmasına neden olmuş ve kristallenme hızı artmış olabilir. Kristallenme hızları Şekil 3'de verilmiş olan \% dönüşüm-zaman grafiklerinden 90,140 ve $160^{\circ} \mathrm{C}$ için sırasıyla $1,52,2,66$ ve $3,4 \%$ /saat olarak hesaplanmıştır.

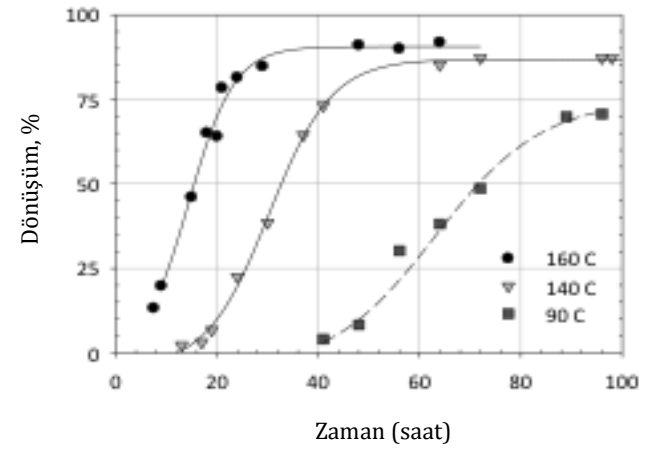

Şekil 3. Sentez sıcaklığının kristallenme hızına etkisi. 
Şekil 4'te kesikli ve geri döngülü sistemde $140^{\circ} \mathrm{C}$ ve 28 saatte sentezlenmiș kristallerin SEM görüntüleri verilmiştir. Her iki sentez koşulunda da sentezlenmiş tozların tane boyut dağılımları tekdüze olmayıp kesikli sistemde sentezlenmiș olan MFI taneleri daha iri boyuttadır.
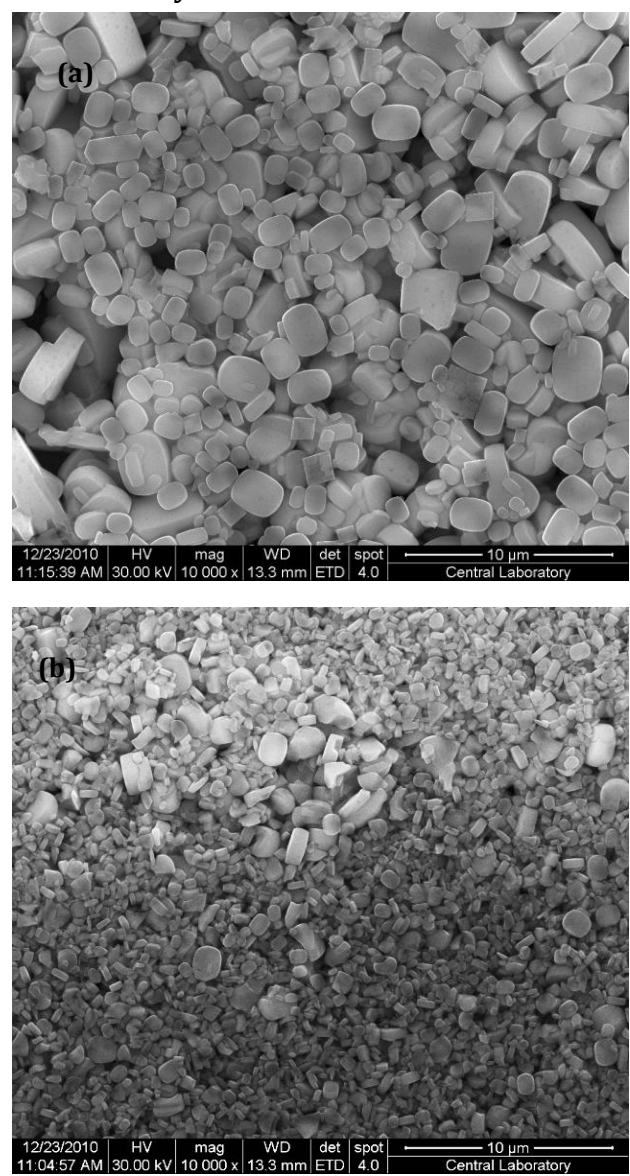

Şekil 4. a) Kesikli ve b) geri döngülü sistemde sentezlenmiş toz kristallerin SEM görüntüleri.

\subsection{Geri döngülü akıș sisteminde MFI tip membran sentezi \\ Sekil 5'de membranlarin} hazırlanmasında tohum olarak kullanılan MFI kristallerine ait (a) X-ışını kırınım deseni, (b) SEM mikrografı ve (c) parçacık boyut dağılımı görülmektedir. XRD deseni MFI kristallerinin saf olarak sentezlendiğini göstermektedir. Tekil dağılımlı $260 \mathrm{~nm}$ MFI kristalleri küresel şekilde olup topaklar içermemektedir.
Tohum kristallerinin topaklanmaması ve nano boyutta olması, sentezlenecek olan membranların morfolojisini, kalınlığını ve buna bağlı olarak da performansını etkilemektedir.
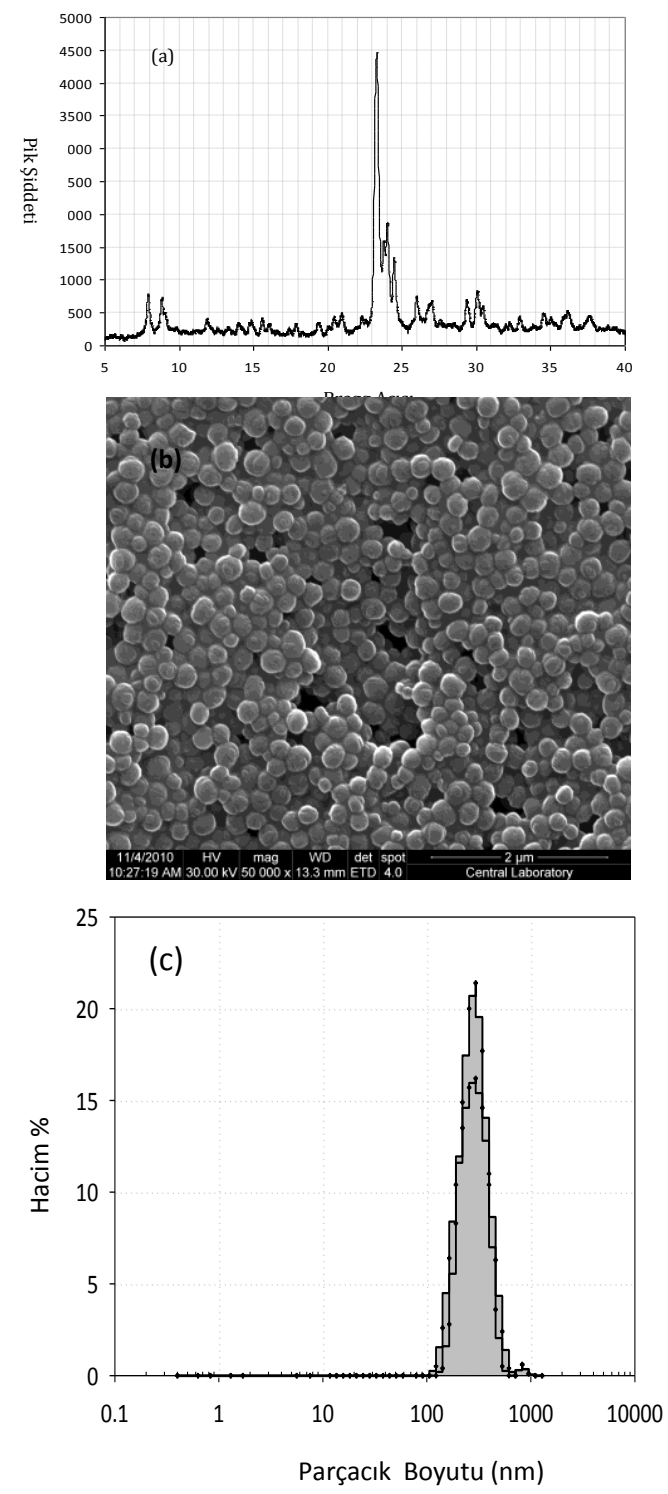

Şekil 5. Tekil dağılımlı MFI tohum kristallerinin (a) X-ışınları kırınım deseni, (b) SEM mikrograf, (c) parçacık boyut dağılımı.

Şekil 6 tohumlu tüp destekler üzerinde geri döngülü sistemde, düşük akış hızında $(10 \mathrm{ml} / \mathrm{dak}), 140^{\circ} \mathrm{C}^{\prime} \mathrm{de} 28$ saat 
süreyle sentezlenen membranın ve membrandan arta kalan tozun X-ıșını kırınım desenlerini göstermektedir. Şekilde içi dolu yuvarlak işareti ile gösterilen pikler $\alpha$-alüminaya, ok işareti ile gösterilen pikler ise MFI tipi zeolit kristallerine aittir. Zeolit kristallerinin hem destek yüzeyinde hem de çözeltide oluştuğu görülmektedir. Alumina tüpler üzerindeki tabaka ve membrandan arta kalan tozlar sadece MFI tipi zeolit kristallerinden oluşmaktadır. Birçok araştırmacıya göre, membran sentezi sırasında oluşan tozda bulunan faz membranı oluşturan faza kanıt oluşturmaktadır [4,21]. Membrana ait

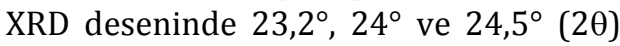
Bragg açllarındaki MFI pikleri (şekil üzerinde detaylandırılarak gösterilmiş olan) oluşan membran katmanının saf MFI fazına ait olduğunu göstermektedir. Membran pik şiddetlerinin toz örneğe göre düşük olması destek üzerinde sentezlenen membranın kullanılan destekten çok daha ince olmasından kaynaklanmıştır. Topuz ve arkadaşları $140^{\circ} \mathrm{C}^{\prime}$ de 24 saat süreyle $55 \mathrm{ml} / \mathrm{dak}$ akış hızının olduğu sistemde ürettikleri membranın kristalinitesini, daha yüksek hızda birikimin az olması nedeniyle, daha düşük olarak rapor etmişlerdir [14].

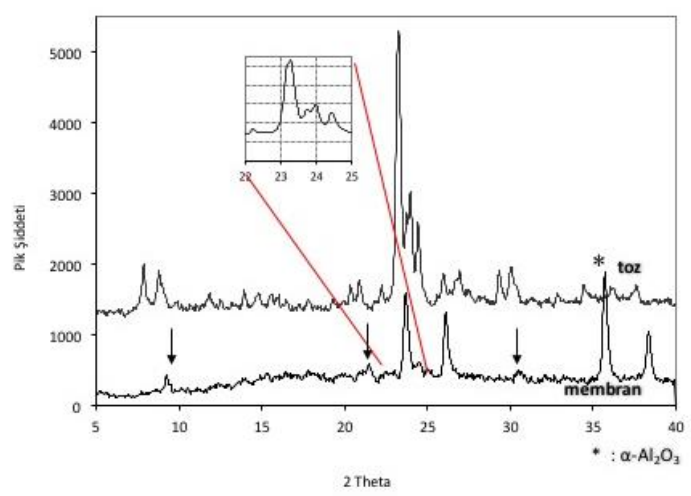

Şekil 6. Düşük akış hızında sentezlenen membranın ve membrana ait toz örneğin XRD deseni (sentez koşulları: $140^{\circ} \mathrm{C}, 28$ saat).
Şekil 7'de $140{ }^{\circ} C^{\prime}$ 'de 28 saat süreyle geri döngülü sistemde düşük akış hızıyla (10 $\mathrm{ml} / \mathrm{dak})$ ve yüksek akış hızıyla (100 $\mathrm{ml} / \mathrm{dak}$ ) sentezlenen membranların yüzey ve yüzeye dik kesitlerinin görüntüleri verilmiştir. Kristal morfolojilerinde akış yönünde herhangi bir yönlenme gözlenmemiştir. Yüzey SEM mikrogörüntüsü sentezleme süresince akış hızı $10 \mathrm{ml} /$ dak olduğunda, membran üzerinde sıkı bir şekilde içiçe büyümüş zeolit kristallerinin yaklaşı $7 \mu \mathrm{m}$ kalınlığında sürekli bir zeolit tabakası oluşturduğunu göstermektedir (Şekil 7a ve $7 b$ ). Akış hızının artmasıyla çok daha ince membran tabakası oluştuğu $(1 \mu \mathrm{m})$ ve membranı oluşturan zeolit kristallerinin ise yine yoğun iç büyümelerin olduğu ve daha küresel bir yapı ortaya koydukları görülmektedir (Şekil 7c ve 7d). Literatürde düşük sıcaklıkta $\quad\left(95-100^{\circ} \mathrm{C}\right)$ sürekli akış sisteminde [11] ve kesikli sistemde [4] sentezlenen membranlarda membranı oluşturan kristallerinin küresel morfolojiye sahip oldukları rapor edilmiştir.

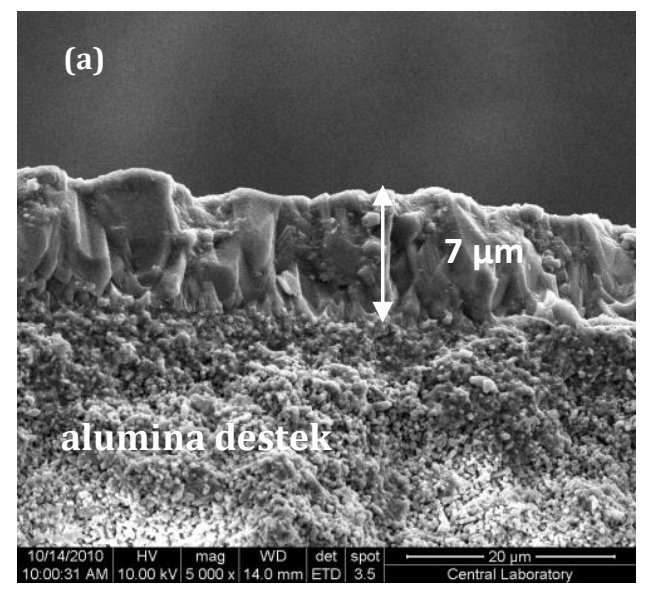


B. Topuz vd. / MFI Tipi Zeolit Membranların Yüksek Sıcaklıkta Geri Döngülü Akıș Sisteminde Sentezi

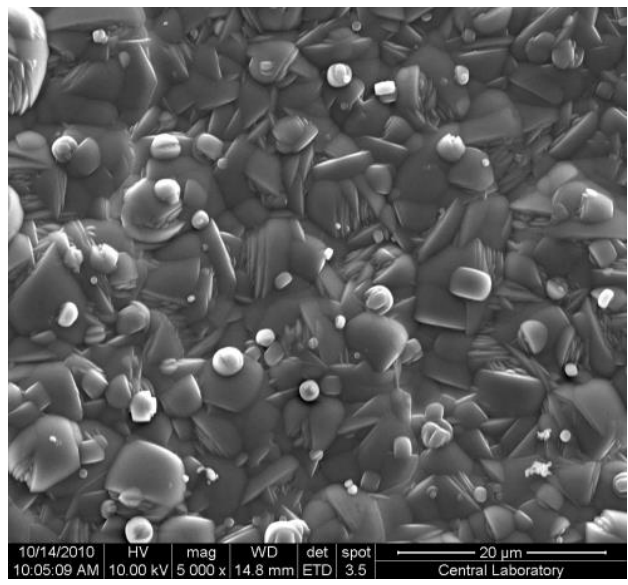

Membran sentezinin $140^{\circ} \mathrm{C}^{\prime}$ de yapilması halinde kendiliğinden 3,2 bar basınç oluşması sıcaklığın $160^{\circ} \mathrm{C}$ 'ye çıkarılması durumunda daha yüksek basinca dayanıklı geri döngülü sistem kullanılması gerekliliğini ortaya koymaktadır. Sistemde daha yüksek sıcaklık ve basınç aralığında çalıșabilen santrifüj pompanın kullanılması, akıș hızının artmasına neden olmuştur. Şekil 8 'de $160{ }^{\circ}{ }^{\circ}$ 'de 28 saat süreyle geri döngülü sistemde yüksek akış hızıyla (100 ml/dak) sentezlenen membranların yüzey ve kesit görüntüleri verilmiștir.

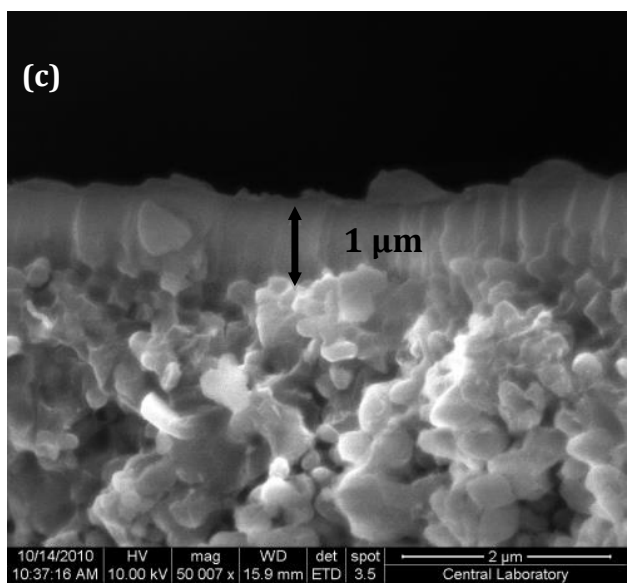
Sentez sıcaklığının artmasıyla membran kalınlığı çok fazla değişmemiş ancak küresel yüzey kristallerinin boyutu azalmıştır.
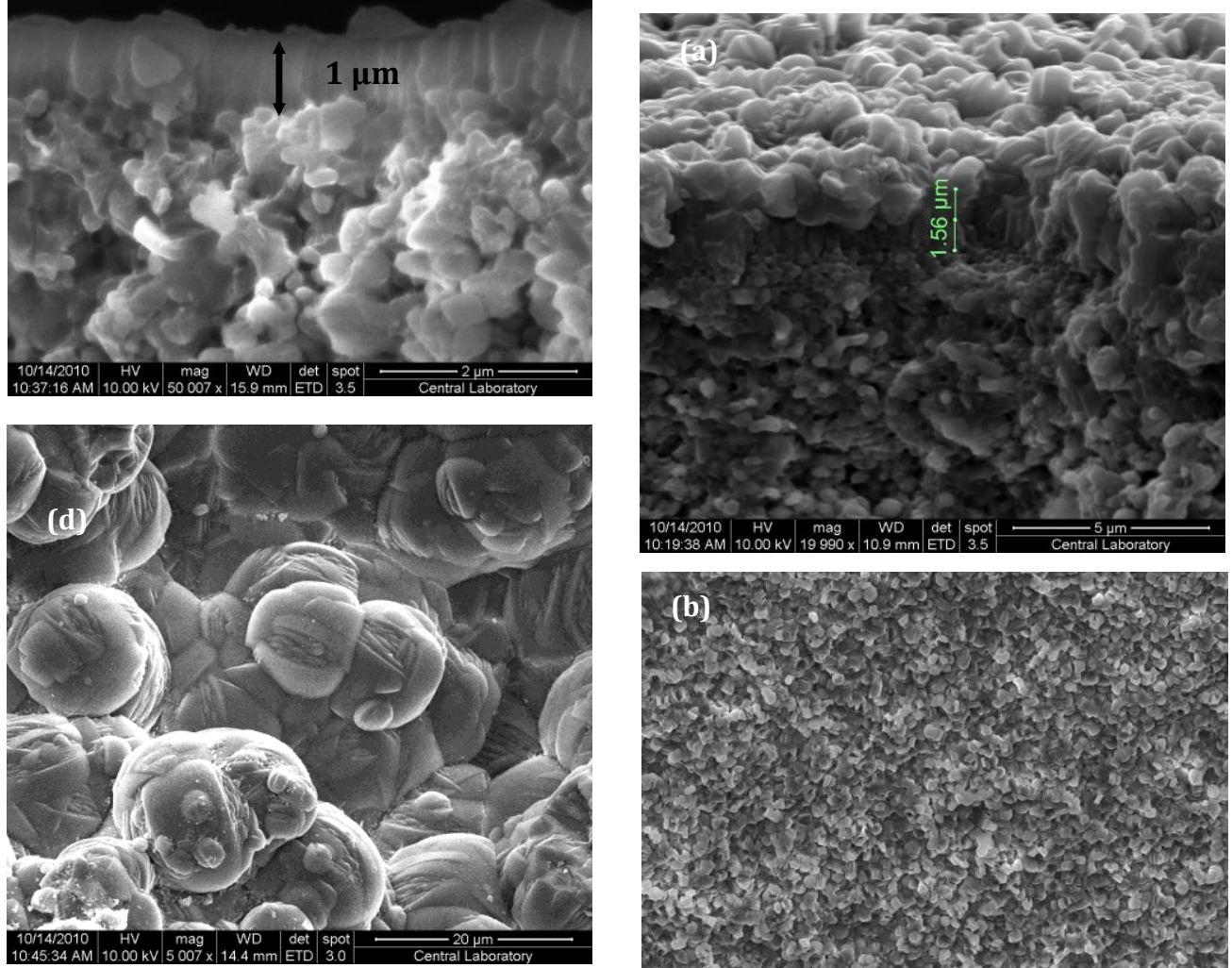

Şekil 7. Tohumlu tüp destek üzerinde 140 ${ }^{\circ} C^{\prime}$ de sentezlenen membranların taramal elektron mikroskobu görüntüleri; akış hızı 10 $\mathrm{ml} /$ dak (a) kesit ve (b) yüzey ve ; akış hızı $100 \mathrm{ml} /$ dak (c) kesit ve (d) yüzey.

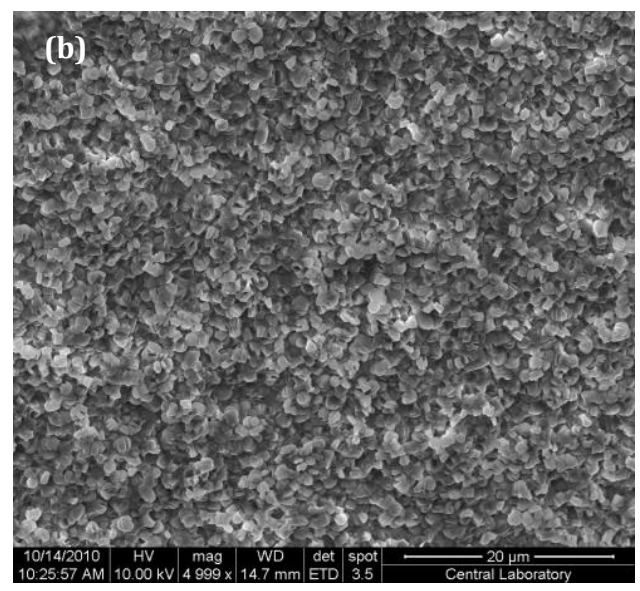

Sekil 8. $160{ }^{\circ} \mathrm{C}^{\prime} \mathrm{de}$ sentezlenen membranın SEM görüntüleri ; (a) kesit ve (b) yüzey. 
3.3. Membranların gaz geçirgenlik ölçümleri ile karakterizasyonu

Bu çalışmada üretilen M1 membranın 25 ve $150{ }^{\circ} \mathrm{C}$ 'de ölçülen $\mathrm{H}_{2}, \mathrm{~N}_{2}, \mathrm{CH}_{4}, n-\mathrm{C}_{4} \mathrm{H}_{10}$ ve iso- $\mathrm{C}_{4} \mathrm{H}_{10}$ tek gaz geçirgenlik değerleri Şekil 9'da verilmiştir. Geçirgenlik değerleri $25^{\circ} \mathrm{C}^{\prime}$ de $\mathrm{H}_{2}<\mathrm{N}_{2}>\mathrm{CH}_{4}<n-\mathrm{C}_{4} \mathrm{H}_{10}$ $>$ iso- $\mathrm{C}_{4} \mathrm{H}_{10}$ sırasında bulunmuştur. MFI $0,55 \mathrm{~nm}$ gözenek açıklığına sahip düz kanallardan oluşur ve adsorplanma özelliği bulunmayan küçük moleküller için geçirgenlik değerleri kinetik çapla orantılı olarak değişmemiştir. Ancak adsorplanma özelliği güçlü olan büyük moleküller için molekül kinetik çapının artmasıyla geçirgenlik değerlerinin düşmesi membranın moleküler elek olarak davrandığının göstergesidir [22]. Sicaklığın $150^{\circ} C^{\prime} y e$ artmasıyla tüm gazlara ait geçirgenlik değerleri artmıştır. Adsorpsiyonun baskın olduğu sıcaklık aralığında sıcaklığın artmasıyla geçirgenlik değerlerinin artması adsorplanan gaz moleküllerinin hareketinin artmasıyla açıklanabilir. $\mathrm{H}_{2} /$ iso- $\mathrm{C}_{4} \mathrm{H}_{10}$ ideal seçicilik değeri sıcaklığın artmasiyla 11'den 16'ya çıkmıştır $\left(\mathrm{H}_{2} /\right.$ iso- $\mathrm{C}_{4} \mathrm{H}_{10}$ Knudsen seçiciliğ i 6'dır). $n$ - $\mathrm{C}_{4} \mathrm{H}_{10} /$ iso- $\mathrm{C}_{4} \mathrm{H}_{10}$ ideal seçicilik değerleri $25{ }^{\circ} C^{\prime}$ de 20 iken, $150{ }^{\circ} C^{\prime}$ de seçicilik değeri 18 bulunmuştur. Yüksek akış hızıyla sentezlenen M2 membranın $n-\mathrm{C}_{4} \mathrm{H}_{10} /$ iso- $\mathrm{C}_{4} \mathrm{H}_{10}$ ideal seçicilik değeri $150{ }^{\circ} C^{\prime}$ 'de 8,5 olarak bulunmuştur. Literatür değerleri ile (Tablo 1) uyumlu bulunan seçicilik değerleri yüksek sıcaklıkta ve basınçta MFI membranların geri döngülü sistemde kusursuz olarak sentezlenebildiğini göstermiştir.

\section{Sonuç}

Bu çalışmada MFI tipi zeolit membranlar yüksek sıcaklık ve basınçta çalışabilen geri döngülü akış sisteminde sentezlenmiștir. Sentez sıcaklığı 140- $160^{\circ} \mathrm{C}$ aralığında değiştirilmiştir. Membranlar alümina tüp desteklerin iç yüzeyinde sürekli ve yaklaşık 1,5-7 $\mu \mathrm{m}$ kalınlığındadır. Üretilen membranların $n$ $\mathrm{C}_{4} \mathrm{H}_{10} /$ iso- $\mathrm{C}_{4} \mathrm{H}_{10}$ gösterdiği ideal seçicilik değerleri literatürde kesikli sistemlerde üretilen membranlar ile karşılaștırılabilir ölçüde yüksektir. Elde edilen en yüksek $n-\mathrm{C}_{4} \mathrm{H}_{10} /$ iso- $\mathrm{C}_{4} \mathrm{H}_{10}$ ideal seçicilik değeri 20 'dir ve uygulanan sentez tekniği yüksek kalitede membranların üretiminin mümkün olduğunu göstermektedir. Zeolit membranların endüstriyel kullanımı için başarılması gereken en önemli aşamalardan birisi de tekrarlanabilirliktir. $\quad \mathrm{Bu}$ çalışmada uygulanan teknik ile tekrarlanabilirliğin arttırılması yönünde çalışmaların yapılması gerekmektedir. Yüksek sıcaklık ve basınçta geri döngülü akış sisteminin kullanımının en büyük avantajı daha büyük yüzey alanına sahip uzun destek malzemeleri üzerinde tekdüze özelliklere sahip membranların üretilmesine olanak vermesidir. 


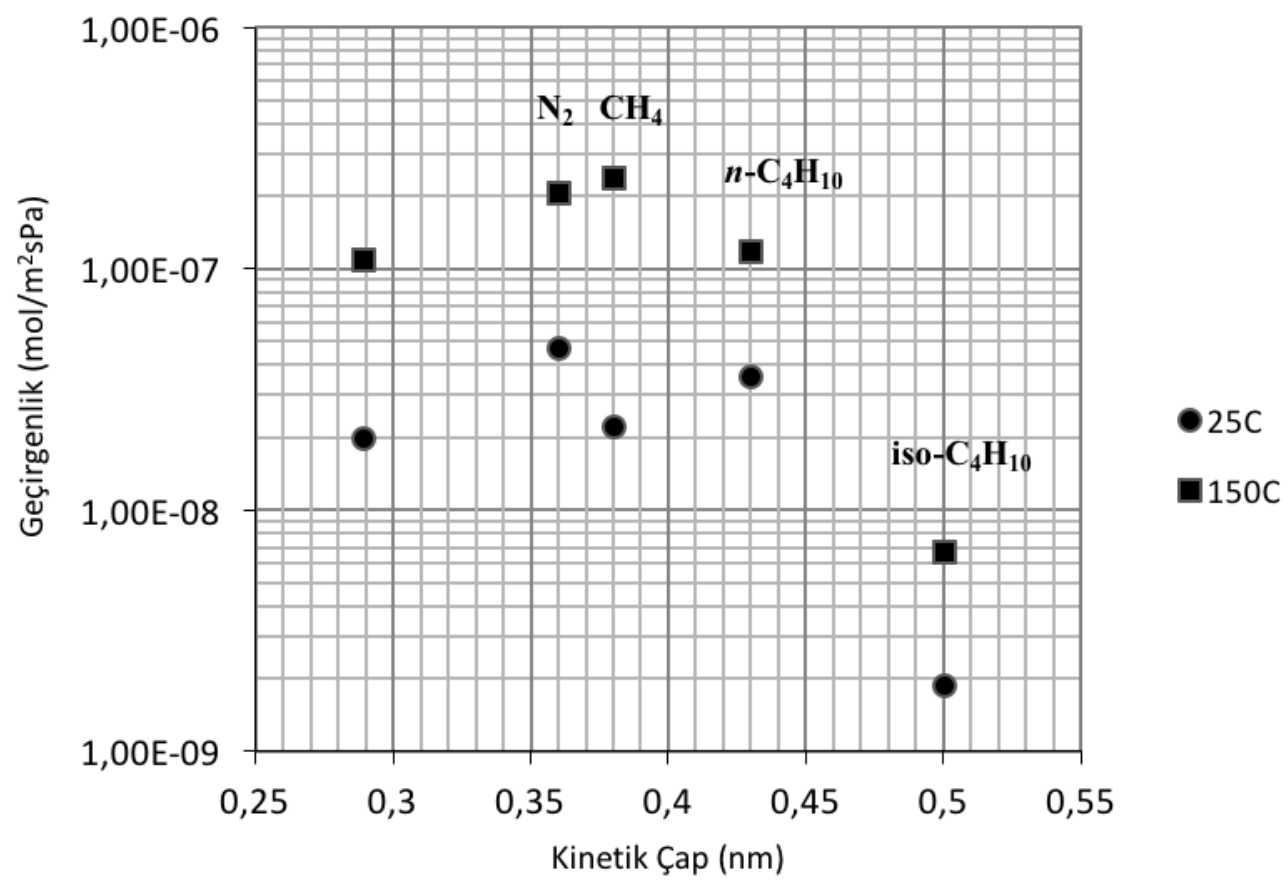

Şekil 9. M1 membrana ait $\mathrm{H}_{2}, \mathrm{~N}_{2}, \mathrm{CH}_{4}, n-\mathrm{C}_{4} \mathrm{H}_{10}$ ve iso- $\mathrm{C}_{4} \mathrm{H}_{10}$ tek gaz geçirgenlik değerleri.

\section{Teşekkür}

Bu çalıșma 110M402 No'lu MAG-ARDEB projesi kapsamında TÜBİTAK tarafından desteklenmiştir. Araştırmacılar desteklerinden dolayı TÜBİTAK'a teşekkür ederler.

\section{Kaynakça}

[1] Kresge CT, Dhingra S.S. 2004. Molecular Sieves, Kirk Othmer Encyclopedia of Chemical Technology.

[2] Breck D.W. 1974. Zeolite Molecular Sieves: Structure, Chemistry, and Use, New York: Wiley

[3] Szostak R. 1984. Handbook of Molecular Sieves, New York: Van Nostrand Reinhold..

[4] Funke HH, Kovalchick MG, Falconer JL, Noble RD. 1996.
Separation of Hydrocarbon Isomer Vapors with Silicalite Zeolite Membranes, Industrial and Engineering Chemistry Research, Cilt 35, s.1575-1582. DOI: $10.1021 /$ ie950495e

[5] Hedlund J, Sterte J, Anthonis M, Bons A, Crastensen B, Corcorand N, Cox D, Deckman H, De Gijnst W, de Moor P, Lai F, McHenry J, Mortier W, Reinoso J, Peters J. 2002. High-flux MFI Membranes, Microporous and Mesoporous Materials, Cilt 52, s.179-189.DOI: 10.1016/S1387-1811(02)003165

[6] [6] Noack M, Kölsch P, Schafer R, Toussiant P, Caro J. 2002. Molecular Sieve Membranes for Industrial Application: Problems, Progress, Solutions, Chemical 
Engineering and Technology, Cilt 25, No 3, s.221-230.

[7] [7] Coronas J, Santamaria J. 1999. Separations Using Zeolite Membranes, Separation and Purification Methods, Cilt 28, No 2, $\quad$ s.127-177.DOI: 10.1080/03602549909351646

[8] [8] Pina MP, Arruebo M, Felipe M, Fleta F, Bernal MP, Coronas J, Menendez M, Santamaria J. 2004. A Semi-Continuous Method for the Synthesis of NaA Zeolite Membranes on Tubular Supports, Journal of Membrane Science, Cilt 244, s.141-150.DOI: 10.1016/j.memsci.2004.06.049

[9] [9] Aguado S, Gascon J, Jansen JC, Kapteijn F. 2009. Continuous Synthesis of $\mathrm{NaA}$ Zeolite Membranes, Microporous and Mesoporous Materials, Cilt 120, s.170-176.DOI:

10.1016/j.micromeso.2008.08.06 2

[10] [10] Çulfaz PZ, Çulfaz A, Kalıpçılar H. 2006. Preparation of MFI Type Zeolite Membranes in a Flow System with Circulation of the Synthesis Solution. Microporous and Mesoporous Materials, Cilt 92, s.134-144. DOI: 10.1016/j.micromeso.2006.01.00 4

[11] [11] Pera-Titus M., Mallada R., Llorens J., Cunill Fidel, Santamaria J. 2006. Preparation of Inner-side Tubular NaA Membranes in a Semi-Continuous Synthesis System, Journal of Membrane Science, Cilt 278, No 1-2, s.401-409. DOI: 10.1016/j.memsci.2005.11.026

[12] [12] Richter H, Voight I, Fischer P, Puhlfür $\beta$ P. 2003. Preparation of
Zeolite Membranes on the Inner Surface of Ceramic Tubes and Capillaries, Separation and Purification Technology, Cilt 32, s.133-138. DOI: 10.1016/S13835866(03)00025-X

[13] [13] Dede Ö. 2007. Pervaporation of Organic/Water Mixture by MFI Type Zeolite Membranes Synthesized in a Flow System, Orta Doğu Teknik Üniversitesi, Fen Bilimleri Enstitüsü, Y. Lisans Tezi, Ankara.

[14] [14] Topuz B., Önder A., Bowen T., Kalıp̧ılar H., 2017. Synthesis of ZSM-5 and SAPO-34 Membranes in a High Temperature-Pressure

Recirculating Flow System, Chemical Engineering Research and Design, Cilt 117, s.746-755. DOI:

10.1016/j.cherd.2016.11.035

[15] [15] Li Y, Zhang X, Wang J, 2001. Preparation for ZSM-5 Membranes by a Two-stage Varying-Temperature Synthesis, Separation and Purification Technology, Cilt 25, s. 459466.DOI: $\quad 10.1016 / S 1383-$ 5866(01)00075-2

[16] [16] Hedlund J, Noack M, Kölsch P, Creaser D, Caro J, Sterte J. 1999. ZSM-5 Membranes Synthesized without Organic Templates Using A Seeding Technique, Journal of Membrane Science, Cilt 159, s.263-273. DOI: 10.1016/S0376-7388(99)000691

[17] Noack M, Kölsch P, Seefeld V, Toussaint P, Georgi G, Caro J. 2005. Influence of the Si/Al-Ratio on the Permeation Properties of MFI-Membranes, Microporous 
B. Topuz vd. / MFI Tipi Zeolit Membranların Yüksek Sıcaklıkta Geri Döngülü Akıș Sisteminde Sentezi

and Mesoporous Materials, Cilt

79, s.329-337. DOI:

10.1016/j.micromeso.2005.01.00

4

[18] Tuan VA, Falconer JL, Noble RD.

1999. Alkali-Free ZSM-5

Membranes: Preparation

Conditions and Separation

Performance, Industrial and

Engineering Chemistry Research,

Cilt 35, s.3635-3646. DOI:

10.1021/ie980808g

[19] Au LTY, Yeung KL. 1999. An Investigation of the Relationship Between Microstructure and Permeation Properties of ZSM-5 Membranes, Journal of Membrane Science, Cilt 194, s.33-55. DOI: 10.1016/S03767388(01)00489-6 